\title{
THE FUNCTIONAL APPROACH - BASIS FOR SUSTAINABLE DEVELOPMENT OF URBANIZED TERRITORIES
}

\author{
Atanas KovaChev $^{1^{*}}$ and Konstantin Kalinkov ${ }^{2}$ \\ ${ }^{1}$ University of Forestry, \\ 10, St. Kl. Ohridski Blvd, 1797 Sofia, Bulgaria, \\ e-mail: atanas_kovachev@mail.bg \\ ${ }^{2}$ University of Economics - Varna, \\ 77, Knyaz Boris I Blvd, 9002 Varna, Bulgaria, \\ e-mail: kallinkov@abv.bg
}

\begin{abstract}
The scientific article seeks the symbiosis between spatial planning and economic development of urban areas or more precisely - the urban area of large and very large cities. The functional approach reflecting the main functional systems - work, living, recreation, service and technical infrastructure, determining the non-transient nature of this approach, was used as a starting point. The development of cities from their formation as a geographical feature with a growing concentration of functions and population over a limited territory to their current state of a complex and dynamic social organism arouses a certain interest for research. Cities require sustainable governance, adequate planning of spatial regulation, functional structure of urbanized areas on the basis of localized and developed economic functions and activities. European cities are home to around $60 \%$ of Europe's population, which accounts for around $80 \%$ of the EU's Gross Domestic Product. On this basis, European cities must ensure economic prosperity and guarantee their own sustainable development.

Keywords: sustainable development, functional approach, urbanized territory, urban territory, spatial planning, economic functions, environment.
\end{abstract}

\section{INTRODUCTION}

The development of cities from their formation as a geographical feature with a growing concentration of functions and population on a limited territory to their current state of a complex and dynamic social organism arouses a

${ }^{*}$ Corresponding author.

DOI: 10.7546/EngSci.LVIII.21.04.01

Engineering Sciences, LVIII, 2021, No. 4 
certain interest for research. Cities require sustainable management, adequate planning of spatial regulation, functional structure of urban areas on the basis of localized and developed economic functions and activities.

The idea of the need for functional zoning of the urban area is dictated by life and it logically appears in some promising avant-garde for its time urban-structural projects, and subsequently it was laid down and disseminated through the Athens Charter. It emphasizes that the city must be functionally zoned, and the "key" functions, such as work, living, recreation and connecting communication, must find their place in it. Historically, for many years this document aroused professional interest among urban specialists. Its positive role in the functional organization of cities can now be really seen. Opponents of the application of the functional approach in the structure and development believe that the strict functionality limits the possibilities for development of the settlement territory. Over time, with the application of the functional approach, it has been proven that each of the basic functional systems contains or may also contain elements from another or more than one other functional system. This circumstance enriches the practical application of the functional approach in the structure and development of cities. The evolution of big cities requires a functional and rational application of the functional approach, so social life can continue to be intensified.

In recent years, a process of investment pressure on urbanized and suburbanized areas has been implemented on the basis of expanding the scope of their economic influence. The result of this process is the complication of the problems and tasks related to the management and sustainable development of cities, as well as the emergence of conflict points between the "centre" and the "periphery". The spatial expansion of the cities due to the developed economic base and the additional population concentrated for this purpose necessitates the extension of the transport axes, connecting the separate parts of these territories. The complex relationships between the various functions and activities in urban areas worsen the ecological balance between the natural and anthropogenic environment and the possibilities for sustainable urban development.

This influence is especially evident when considering the city from a spatial (structural) aspect. The change is introduced by modern urbanization processes and is based on the fact that the city is no longer seen as a point of settlement, but as a highly developed urban area. The modern metropolis enters the adjacent territory, which is required by the modern features of the economic and infrastructural base of urbanization. The development of the 
peripheral parts of the urbanized territories is also connected with the spatial aspect, i.e. with the process of suburbanization.

In economic terms, the urbanized area (city) is the localization and development of economic functions and activities, and on this basis, of urban services provided. The process of urbanization determines the increase of the economic influence of the city, including influence on the adjacent territory, i.e. an economic field of influence on a larger territory is created.

Socio-demographic aspect. The globalization and internationalization of urbanization processes create conditions for the wide spread of urban lifestyles. The strongest impact on the modern urbanization processes, related to the social-demographic aspect, is the one of commuting, which is a mass phenomenon for almost all countries.

The aim of the authors in this scientific article is to analyze the role and importance of the functional approach in the sustainable development of cities.

The object of study are urbanized areas and more precisely the territory of cities, as highly urbanized areas.

In the present research, the authors do not claim to have considered all aspects, related to the emergence and sustainable development of cities. The consideration and analysis of the connection between the spatial, economic and socio-demographic aspects of the cities are the subject of a larger author's research on the topic of "Theories and Models for Spatial and Economic Development of Cities" (See in detail At. Kovachev, 2013). From this point of view, the consideration of the functional approach as a basis for the sustainable development of cities is a part of this basic study. Despite this fact, the application of the functional approach is a starting point for the sustainable development of cities from their inception until now, based on the fact that the centre is the person with his daily needs. It is this feature that makes the functional approach avant-garde for its time, and applicable in different epochs and economic systems.

\section{THE ATHENS CHARTER - A BASIS FOR APPLYING THE FUNCTIONAL APPROACH IN THE STRUCTURE AND SUSTAINABLE DEVELOPMENT OF CITIES}

\subsection{The Athens Charter (1933)}

In 1933 the fourth congress of the Congres Internationaux de L'Architekture Moderne organization is held in Athens (See in more detail M. Todorova, 1984). The decisions of the congress are further processed by Le Corbusier, 
and published 10 years later. The Athens Charter became a manifest of modern urban structure. It determines for decades ahead the direction of urban thinking and action. The Athens Charter does not exhaust the whole platform of modernism and the theses in it are not pushed to their extreme. The main thing in the Athens Charter is the segregation of functions. In it, the main functions of urban planning are reduced to the following four types - living, work, recreation (leisure) and movement.

This view of urban planning contradicts the hitherto existing view that the only problem to urban development is movement. Back then, the current opinion on urban development was related to the requirement that it only took to draw the avenues, to determine the directions of the streets, and to create the quarters, the purpose of which remains a private initiative.

The Athens Charter also includes the idea of territorial segregation of functions, which in the current conditions of urbanization are perceived as a constraint on the development of cities. The Athens Charter provides for the industrial sectors to be independent of the housing sectors and to be separated from them by a green zone. The motive is to separate large factories located in residential areas, which worsens the living environment, but this view does not apply to small-scale production activities close to housing, which is defined as harmony disrupted by industrial development.

In the modern reading of the Athens Charter, the sharp criticism to the disregard for the social orientation of the city development, the opposition to social inequality, the opposition to unlimited private ownership of construction land as a source of speculation and a constraint on urban reform are striking. At the same time, the creators of the Athens Charter strongly defend the need for plan-following urban development, so that the city is considered and planned together with its area, i.e. with its adjacent territories. On this basis, Le Corbusier's view is that urban land, residential quarters and homes themselves depend on people pursuing enrichment goals. The question of combining individual and public interest excites Le Corbusier no less than purely professional matters. On this basis, the view is that life develops only if the two opposite principles that govern man are combined - individualism and collectivism. With these words begins the Athens Charter and ends with almost the same.

One of the sharpest criticisms against modernism is directed exactly against the urban-structural practice of strictly functional zoning, sterile, thoughtful, inspired by the principles of modernism itself, which does not always correspond to the real-life processes taking place in the city. A characteristic 
disadvantage of modern urban structuring is its inability to ensure cultural continuity.

Major changes should be expected in the specific ways, in the specific tools for the implementation of urban development plans. Instead of administration in market conditions, the role of investment risk increases, which regulates investment intentions and creates conditions for achieving a balance between public and personal interests in society. The problem of the balance between individual and collective interest, set out in the Athens Charter, is becoming relevant again today. This circumstance implies an increase of the role of civil society for solving modern problems related to urban development.

The problems related to the development of modern cities are considered to be the ones of the biggest global problems. Experts in this field predict a crisis in cities due to economic collapses, increasing social problems, severe moral and physical depletion of the building stock and supporting public-welfare systems. Conditions are created by analyzing the most acute problems of the cities for the implementation of various schemes for their solution. In this respect, great importance is assigned to urban planning. Difficulty lies in the fact that it must be carried out in a complex and unusual in terms of current governance economic environment, and established traditions and habits in society.

One of the main problems is related to stopping or limiting the territorial expansion of cities, i.e. their extensive development. Analyses show that there are enough and still underused territories within the city limits. In this regard, the recommendation is to stimulate the compact, intensive development of cities by applying special norms, taxes and fees. The compact growth of cities creates conditions for solving transport problems as well. Compact development with high living density and maximum variety of established urban functions is the modern ideal for urban structure. The vision is to ensure through various measures the construction of a wide range of different types of comfortable and luxurious housing, including smaller and cheaper ones for different social groups, in order to avoid social segregation.

Regardless of technical progress, urban-structural solutions are the tools that are heavily relied upon to solve urban problems. On this basis, the requirement is to analyze and use the concrete and specific features of each city as thoroughly as possible. To apply urban planning solutions with maximum ecological effect, leading to sustainable development of the urban territory. To this end, land use control is included to prevent encroachment on society's rights and individual freedoms. This is especially relevant now, in our reality, 
on the basis of emerging public sentiments as a reaction to the hitherto limited individual freedoms.

The concept which will determine the future development of cities is the concept of sustainable development.

With the update of the Athens Charter at the end of the twentieth century, the population was placed at the head, thus bringing to the front the problems of sustainable urban development. The authors of the Athens Charter, even at its creation, raise the issue of separation of production activities from the living areas, which is a start of solving the environmental problems of the city. Sustainable urban development requires synchronized and balanced economic, social and ecological development of cities. This point is enshrined in the Glossary of Territorial Structure of the European Union, published by the Council of Europe in 2007, where the term sustainable territorial development includes economic, social and ecological development of the territory.

\subsection{Update to the Athens Charter (New Athens Charter - 1994)}

\section{The modern European city}

In 1994, a conference was held in Athens entitled "Towards a New Athens Charter - From a Limited City to a City of Citizens". At this forum, urban planners discuss the effect of the 1933 Athens Charter on European planning theory and practice, and propose a new charter to be drawn up to address the challenges and possibilities facing European cities now. The idea was accepted, and its implementation was continued in 1995, when the European Council of Urbanists (ECU) held a conference in Athens. The participants in the conference took a decision reaffirming the need for a new charter to accelerate the development of European cities in the $21^{\text {st }}$ century. The new charter is the result of the efforts of institutes, organizations and urbanists from 11 countries in Europe. The Charter is the principal basis of the international conference "New Charter of Athens 1998".

The new charter reflects the wide spread and influence of the Athens Charter of 1933, and the shortcomings of the types of structures and schemes, the result of the application of the charter. In the preparation of the new charter for the development of cities in the XXI century, the citizen is firmly placed in the centre of the implementation of urban structural policy. The basic concept enshrined in the new Athens Charter is that the evolution of cities must stem from a combination of a variety of social factors and the actions of key players in the urban development process. From the point of view of the ECU, a new 
framework defining urban planning is needed in order to meet and respond to the social and cultural needs of the present and future generations.

In recent years, sustainable development has been a major issue for urban development. Urban planners have realized the need to apply the principles of sustainable development as a fundamental part of urban planning and development. Modern cities generate significant amounts of waste and pollution of the urban environment, which leads to a general deterioration of the quality of the environment and the overall urban standard of living. The requirement to create a more sustainable city is one of the biggest challenges to urban planners in the $21^{\text {st }}$ century. Along with solving the problems related to the degraded qualities of the environment, there is a need to solve the problems with the protection of the cultural, historical and architectural heritage of the cities, the open spaces and the systems of green zones in the spaces around the cities. The maintenance of biodiversity is in a critical condition, and it is therefore equally important for resolution, both in cities and in agricultural areas. Energy storage is also an important component of the overall framework of urban planning.

Economic issues have always had a strong influence on the shaping of cities. The structure of the EU has changed significantly rapidly over the last two decades. The process has been disrupted by two deep recessions, which in turn are affecting both manufacturing and services industries, in both public and private sectors. Although European economic activity will continue concentrating in cities, there are several trends that may affect future urban planning. Economic development, including partnerships between the public, private and voluntary sectors, will play a fundamental role, but will require transparent procedures, respectively. From this point of view, the process of economic restructuring is expected to proceed rapidly. At the macroeconomic level, there will be growing competition between cities to attract jobs. Internationally, there is a tendency to limit large enterprises and a change in labour practices, leading to large-scale and long-term unemployment.

Several issues about the management of urban activities and the structure of urban territory influence the determination of the urban form. One of them is the issue of centralization, in which facilities and services are concentrated around the central city core. Another one is the issue of dispersion, where the new spatial developments extend territorially outside the urban core to the peripheral areas, connected to the suburban areas. These spatial issues are on the agenda for resolution in the $21^{\text {st }}$ century through urban development plans.

The expansion of the central city does not take into account the problems, created on the city border and beyond it. In the sprawling city, the problems 
of proliferation are felt more at the subregional level. Subregional planning is needed to ensure hierarchy in urban development on the basis of ensuring a clear functional link between the city centre, its suburbs, peripheral areas and connected cities, in the urban region. In some areas, the concept of urban congestion may be a priority. In certain cases, a settlement formation of cities can be created, in which each individual city can preserve its identity and have a specific goal for its development on the basis of a created quality system for mass urban transport between the individual settlements.

\subsection{Vision for the development of the city in the XXI century (New Charter of Athens - 2003)}

In the $21^{\text {st }}$ century, the European Union will achieve its main goal of integrating the European Economic and Physical Space. On this basis, the widespread vision for the future of European cities is presented.

The vision of the new Athens Charter from 2003 is a message addressed primarily to urban professionals working in Europe, and to those involved in the planning process in order to provide guidance for better coherence in building a meaningful network of cities in Europe connected over time at all levels and sectors.

Spatial planning is vital to ensure sustainable urban development. It specifically affects the reasonable management of urban space, and the critical natural resource is the land, which with its territorial limitations and quantity has always been subject to additional growing reqirements.

During the second half of the $20^{\text {th }}$ century, many negative predictions were made about the future of European cities, including declining productivity, lagging behind of central areas, uncontrolled crime, severe pollution and a dramatic decline in environmental quality, as well as loss of identity. These predictions did not materialize, despite the fact that the cities of the old continent are far from the necessary and ideal conditions for development, and are faced with great challenges.

In response to these challenges, a vision is offered that focuses on the Connected City, essentially a snapshot of what we would like our cities to be now and in the future. The Connected City consists of a variety of binding mechanisms, operating at different scales. These include tangible and visual connections to the built environment, as well as connections between the diversity of urban functions, infrastructure networks and information and communication technologies.

The problems of the current city are due to the lack of connectivity that means consistency not only on the principle of built environment, but also on 
identity, which is an important element for the development of the city and must be preserved in today dynamic world. In the future, the concept of a "network city" must focus on a series of polycentric urban networks, many of which transcend the national borders of new Europe.

The leading goal of urban development is the sustainability of urban environment, which contains the integration of economic, social and environmental dimensions of change based on the active participation and commitment of urban population.

$21^{\text {st }}$ century European cities will be strongly connected with respect to economic level, challenging the creation of a highly interdependent financial system with high efficiency and productivity, maintaining high employment levels and ensuring the necessary competitiveness in the global market, adapting dynamically to changes in external and internal conditions. Economic activities are influenced by two main forces - globalization and specialization (local or regional). On the one hand, new economic activities are based on the knowledge, and more and more innovative technologies will be applied in production and services. In this context, cities need to make strategic choices about their economic orientation. In the $21^{\text {st }}$ century, cities that capitalize on their competitive advantages will be economically successful. This goal is related to achieving a high degree of commitment at many levels. The successful development of a city depends on the effective use of the best of its existing attributes, which are both endogenous and exogenous to the city, in order to localize economic activities. In order to increase their competitive advantages, individual cities are forced to join different networks that function more efficiently when they are more or less integrated, with cities being nodes connected territorially.

Defining new urban networks and positioning individual cities within the network require a significant commitment from of the local executive authority related to the implementation of the spatial strategy.

The economic cohesion of European cities will not reduce their diversity, but will contribute to it, while participation in a common system will promote specialization and diversity based on the competitive advantage of each individual city.

One of the main contributions of global communities, such as the European Union, in the $21^{\text {st }}$ century will be the new model for the development of its ancient and modern cities. Cities that are really connected, that are innovative and productive, creative in science and culture, and are the centre of ideas, creating modern living and working conditions for their people, i.e. cities that will connect their past with their future through an optimistic present. 
The concepts of sustainable development, urban identity, public life, security, education and health are becoming key elements in urban planning.

\section{SUSTAINABLE DEVELOPMENT OF THE URBANIZED TERRITORY - A GUARANTOR OF SOCIO-ECONOMIC PROSPERITY}

\subsection{Urban planning and sustainable development}

Practical experience shows that in the last 60 years cities have developed arbitrarily, not even the established urban models have been applied. In most cases, their development is subject to principles related to turbulent urbanization processes. These principles may be constant over time, or follow certain trends, but they must be properly understood before new ones are introduced. The proposed new urban planning principles are grouped into two broad categories as follows:

A. Basic principles developed in the past, which in most cases are universal;

B. New model principles proposed for the XXI century.

The new basic principles proposed for urban development are not thorough, which suggests that they form a basis for discussions in this area. In recent years, there has been a trend towards more open consultations related to the dissemination of information on urban development plans and schemes. In order for urban planning to be more effective, it is necessary to conduct a wider dialogue with more specialists in this field. For the realization of this dialogue, urban specialists actively support the local government, business, non-governmental organizations in order to ensure and reach consensus on key issues related to the problems affecting the development of the city. So far, the practice of monitoring city plans by the executive authority has been adopted in accordance with the legal and regulatory requirements in this area. Information on urban planning is of particular importance for determining trends in the development of the city. The basis for making the relevant decisions is determined by the priorities for the development of the city determined on the basis of the goals set and the indicators related.

The spatial elements, including the location of the city as well as its social structure and the main resources of the urban area, are always subject to city planning. Other factors related to the development of the city are relief, climate and the existing structure of land use. Other elements of urban planning are the plots (land), buildings, wooded areas, waterways, transport network, open urban spaces, sites representing the cultural and historical heritage of 
the city, as well as the administrative-territorial boundaries. It is especially important for the development of the city to connect the urban area with the surrounding region.

These factors are especially important in determining the shape of the city and the surrounding area. The role of the central city core has not disappeared from the development of the city, despite the increased mobility and the application of modern information technologies. For centuries, urban life has been organized through the connection between certain central places and the territory between them. Stopping this process is suddenly not possible because the destabilization of some traditional centres due to the relocation of trade and economic activities from them to the peripheral areas of the city creates a condition for the revival of new urban centres. The emergence of new urban centres requires special attention in the implementation of urban planning with an emphasis on creating a high-performance urban environment. The facts show that the future of the city is related to its polycentric structure, not to the development of a monocentric structure. In this context, mixed-purpose places, where citizens can live and work, are supported according to specific needs, instead of imposing a strict policy of functional zoning in urban-structural plans.

Cities are planned on the basis of their overall scale and functions taking into account environmental criteria and the principles of sustainable development. In this direction, a strategic and global assessment of all active factors related to the economic, social and ecological environment has been made. This global approach, often involving Strategic Environmental Assessment, is one of the guiding principles of sustainable development. On principle, there are no technical limitations to using this approach, except for the lack of sources for collecting relevant information. Modern means of information processing create conditions and make it possible to solve the problem of complexity.

In the future, cities will continue being drivers of economic development and they will influence the socio-economic prosperity of the surrounding agricultural areas. The cycles of urban development models have always been the subject to extensive review based on long-term observations and predictions. What is special, is that hasty actions and decisions, whether of a political or economic nature, always have an indefinite effect on the development of the city. In the same way, the preliminary implementation of activities and projects without the necessary technical justification or in underestimation of the specific local features or the possibilities of the capacity of the urban environment leads to errors in urban planning. Taking into account all these 
circumstances in the implementation of urban planning, a thorough review of economic, social and environmental issues related to the urban environment should be made together with predictions and trends for the development of the city.

In this context, urban planning guarantees the public interest, which should not be underestimated and ignored. Very often, urban planning is used to resolve conflicts and interests, and to mediate between different social groups. Conflicts can be overt or covert, but their very presence requires the need to resolve them, which inevitably affects urban planning.

The new principles of urban development in the $21^{\text {st }}$ century rely on urban resources, which are distributed more fairly according to the principles of justice, local needs and support. The distribution of spaces between built-up areas, protected and green areas and recreation areas is extremely important for the development of the urban area. The mutual exchange between these zones leads to the predetermination of the city as a sum of urban zones, which in some sense can be connected with the concept of urban identity. Open spaces, green spaces and natural areas are an essential element of the urban-structural policy of any city, and they are used to provide a pleasant environment and landscaping of the city. The green areas in the city and its surroundings need to be managed with the means of landscape art.

The creative role of urban planning is evolving to meet the needs of the city and its society. Adherence to the new principles of urban planning requires the influence of urban specialists on the processes related to solving issues for sustainable development of the city.

The primary role of urban planning is related to the provision of a spatial framework of the settlement territory for future planning and development of the city. The scope of urban planning is much wider and unique, and has an interdisciplinary nature compared to other disciplines. Urban planning is a centre for achieving balance and synchronization between public and personal interests in society, which requires communication between experts, local authorities and representatives of civil society. Urban planning can ensure and achieve the adoption of a plan or program that have been extensively discussed in society through mediation between different professional and social groups by influencing important key decisions and by bringing to the fore alternative assessment options.

\subsection{Localization of economic functions in the urban area}

The city has a significant role for the development of the national economy. It is on its territory that in most cases the financial and commodity markets 
are concentrated, and decisions are formed that are important and give the course of economic life in the country. The economic activity of the urban area is a kind of a mediator between consumers, producers and local governments. From this point of view, many urban economists suggest considering category "city" together with such fundamental categories of economic analysis as "consumer" and "enterprise".

The city is an independent economic agent that makes decisions for business operations for its subsistence and income of the population. The effect of the agglomeration economy is related to the public interests of various economic agents operating on the territoey of the city. The long-term economic role of the city is displayed when the internal analysis moves to its spatial structure, i.e. to studying the functioning of its structure. In this way, the concept of "functions of the city" is also included, which is necessary as a tool for the implementation of spatial economic analysis. The study of these functions allows the reflection of the specifics of each city. Within the classical economic analysis, the city is considered primarily as a production system, emphasizing on the functions and activities of companies on its territory. From the distribution of these companies by main industry groups, we get the idea of the predominant orientation of the city to one or another type of production.

The examination of the companies leads to an analysis of the markets and the factors of production presented in a given city, and here the integrating infrastructural role of the city is manifested, as well as the factors of production necessary for the companies of different branches. Thus, in the city for each of these factors (labour, financial resources, various types of equipment, semifinished products, raw materials, production sites, services, etc.) the total effect is obtained. The city ensures the emergence and profitable operation of many companies, concentrates a workforce with different levels of qualifications and a wide range of specialties. The effect of agglomeration is observed in the city. On the other hand, the companies - producers of final products, need market for their products, which they partially find on the territory of the city, in which they are located, and thus meet the needs of its population.

This complicated economic situation imposes the need for respective specialization of urban areas, both on the scale of the system of cities and within the city limits. Particular attention is paid to those industries that provide a higher gross income per unit of urban area, type of activity and type of services. These economic activities are located in strategically important large cities. On the territory of these cities, the main types of services of urban and regional importance occupy the central urban area. Activities related to the secondary and partly to the tertiary sector oriented mainly to the extensive 
form of land use (industrial enterprises, warehouses, transport terminals, etc.) are in the second echelon of the city, and usually they occupy the suburban area of the metropolis.

This circumstance is a centrifugal tendency of deindustrialization, which changes the functional orientation of the city and the respective distribution of experts on the labour market, creating a flow of migration. Thus, a problem arises in the city - the need for requalification of the workforce. These processes sharply change the situation in the field of employment, which determines the interest of the city authorities in determining the long-term functional profile of the city.

Such an approach is particularly evident in the policy of the new cities, which have been created for the realization of some dominant functions. The ideas of functionalism characteristic of the 1920s and 1930s are often associated with the name of Le Corbusier and his followers, who had a great influence on the general principles for the formation of the system of cities.

The methods of modern functional analysis allow the improvement of the morally outdated system of segregating the functions of the city into the three main sectors of the economy. The ability to process a large array of data creates the conditions to move to application of the functional dominance of the city.

One of the essential features of the XX century and the beginning of the XXI century is the rapid development of cities and the high trend of urbanization and suburbanization. The consideration of the role of urban growth is related to the economic theory of urban development as part of the spatial economic theory, as well as to the concepts of the implemented urbanization policy.

The emergence of economic theory of urban development is preceded by a number of publications in classical economic theories, which examine the changes that occur in cities in the conditions of emerging production relations and their role in the territorial organization of social production. Later, with the development of the theory of the territorial location of the productive forces, the question of the regional role of the city and its place in the regional structure became central.

The specific features of urbanization processes in science are determined by their application in the study of economic activities. The impact on the territorial concentration of business activities within the framework of urban development is associated with the spatial localization of production or distribution of consumption. The change in their structure is determined by technological changes, population density, population income dynamics, transportation 
costs, forms of combining activities in urban centres and their relation to the periphery.

The differences in the production and market conditions in the elaboration of the problems of their urban localization require the use of different principles of localization. Initially, the classical principles of localization are used taking into account the product differentiation in the emerging savings and the specifics of merging certain industries at certain points, which affects trade operations in space.

Practice shows that most cities have many plans that contribute to the sustainable management of the urban environment. On the other hand, very few of these plans address all respective principles and no plan includes all the policies and programs needed for sustainable urban management. Although there are many plans in each city that govern urban areas, few of them follow the principles of sustainability, and even fewer are synchronized and harmonized with each other. Very rarely, plans to promote economic development are harmonized with territorial plans. Practice shows that in most cities the mosaic of existing plans is an incomplete and fragmentary approach to the urban zones management in a sustainable way.

A small number of major European cities are run by a single administrative body. In many metropolises there is a management deficit in terms of sustainable urban management. This fact determines that only if all administrativeterritorial units managing the urban area join the principles of Sustainable Urban Management, it is possible to manage the entire urban area in a sustainable way. All cities and towns function as economic markets, in which the administrative-territorial units compete with each other for investments in education, healthcare, recreation, trade, business, housing construction, etc. In addition, they are present on the market in order to attract and retain the population in order to achieve sustainable urban communities. The activity of this market can seriously disrupt the sustainable management of the urban environment by actively working against the principles of sustainable urban development.

National and regional authorities can intervene in this market by using a regulatory framework that allows neighboring local communities to cooperate rather than compete for investment. A regulatory and coherent planning framework for allocation according to the principles of sustainability of land use, transport, infrastructure within the metropolis or subregional zone allows each administrative-territorial unit to subsequently manage its own territory in a sustainable way. Thus, they can agree to cooperate to achieve a certain goal by uniting the territorial communities on a certain range of tasks. Coherence 
and cooperation between the respective plans are particularly important for achieving sustainable management of the urban environment throughout the urban area. Individual European countries give territorial communities considerable autonomy with regard to territorial planning, but do not provide a regulatory or coherent planning framework for competition management. Evidence of this fact is that territorial communities cannot manage their urban areas in a sustainable way, which leads to urban sprawl. The implementation of a strict framework for subregional regulatory planning helps to direct investment to the most sustainable places, to regenerate urban areas, and to create a harmonious living environment.

\section{RECOMMENDATIONS}

On the basis of the analyses and conclusions, made in the analytical part of the scientific article, the authors have shaped-up and made three proposals, namely:

a) According to the authors, the basis for sustainable development is the regional level, so they propose the administrative-territorial reform to be implemented, and the planning areas, which are now territorial units under the Regional Development Act, to become administrative-territorial units with their management structure and their own budget.

b) The authors of the scientific article taking into account that processes related to sustainable development are not at rest, but have their dynamics, believe that the characteristics, structure and content of sustainable development can be upgraded, including in accordance with the objectives of any given study. From this perspective, unlike the classic definition of sustainable development involving three main elements - economic, social and ecological, the authors propose that the structure of sustainable development in spatial planning should include the following three aspects:

- territory/spatial planning;

- investment/economic functions;

- population/workforce.

The balance/parity between these three aspects creates the basis for the sustainable development of urbanized territory.

In conclusion, sustainable development in the symbiosis between structural planning and economic functions should be perceived as balance/parity between: territory-investments and population in the conditions of leadership and importance of the executive authority. This sustainable development is linked to the increase in the living standards of the population on the basis of the higher Gross Domestic Product per capita achieved. 
The proposed definition of sustainable development is in line with the National Plan for Reconstruction and Development of the Republic of Bulgaria. The Recovery and Sustainability Mechanism is part of the "Next Generation of the EU" element (2021-2024) under the Plan to Rebuild Europe.

Another view of the authors of the article on this issue is that it is necessary to develop an Urban Strategy on the territory of the Republic of Bulgaria, on the basis of the investment attractiveness of the urbanized territories. This will close the circle of strategies connected to sustainable development, namely: urban, economic and demographic - the basis of which is the proposal to upgrade the definition of sustainable development.

\section{CONCLUSION}

Sustainable development is a fundamental goal of the EU, which is enshrined in the Treaty of the European Union, and for a long time has been at the basis of the European project. The EU Treaties recognize the economic, social and ecological dimensions of the EU, which should be viewed together. During recent years, the EU has shown its strong commitment to achieving sustainable development and has successfully incorporated it into many of its policies. Sustainable development means a better way of living. The idea of sustainability implies that economic growth, social cohesion and environmental protection go hand in hand, and complement each other.

The global economic and financial crisis shows that sustainable development is essential. Restoring confidence in the financial system and the stability of the economy are key objectives of sustainable development. Sustainable development should not be seen as a stagnant process (constantly related to production and consumption), but as a dynamic process, in which innovations in the economic, social and ecological fields find their wide range of application.

The problem of sustainable development is global and unprecedented in its scale and forms of manifestation. It is unsolvable without regional and national goals and strategies for its implementation. The Programme for Sustainable Development and the Sustainable Development Goals till 2030 are fully in line with the vision for Europe, becoming a global concept for global sustainable development. The program states: "The 2030 program integrates in a balanced way the three dimensions of sustainable development - economic, social and ecological" (European Actions for Sustainability, 2016).

Cities and local authorities have a special role in EU's concept of sustainable development. Cities are closely familiar with economic, social and ecological challenges. Cities are the engine of the European economy and function as cat- 
alysts of innovative solutions for sustainable development. EU's Programme for Cities is being implemented through a integrated approach together with local authorities, covering all aspects of sustainable development, and is contributing to the execution of the global "New Urban Program" (adopted in October 2016).

Sustainable development will not only be achieved through public sector policies. For this purpose, it is necessary to create a dynamic space that unites the various interested parties from the public and private sectors. EU's goal is to integrate sustainable development goals into policies and initiatives, making sustainable development a key guiding principle of all European policies. Existing and new EU policies should take into account the three pillars of sustainable development, namely social, ecological and economic issues.

\section{REFERENCES}

[1] Al. Alexandrov, Theoretical Foundations of Urbanism, UACEG, Sofia (2006).

[2] European Sustainable Action (2016) \{SWD/2016/390 final $\}$.

[3] K. Kalinkov, Urbanism, IC "Gea-Print", Varna (2010).

[4] At. Kovachev, Territorial Structure, Pensoft Publishing House, Sofia (2009).

[5] At. Kovachev, et al., The City, IC "Gea-Print", Varna (2013).

[6] At. Kovachev and K. Kalinkov, Thesaurus, Varna, Gea-Print Publishing House (2011).

[7] At. Kovachev, Urban Planning, Part 1, 2, 3 and 4, "Vanguard Prima", Sofia (2019).

[8] National Concept for Spatial Development for the Period 2013-2025, Adopted with Protocol No. 47 at a Meeting of the Council of Ministers on 19.12.2012.

[9] V. Penchev and R. Pencheva, Sustainable Development - Theoretical and Practical Dimensions, VTU "St. St. Cyril and Methodius" (2017).

[10] M. Todorova, Original Concepts in Modern Architecture, "Technique", Sofia (1984).

[11] St. Totev, Regional Strategy for Economic Development, Gorex Press Publishing House, Sofia (2008).

[12] M. Shishmanova, Trends and Problems in the Structure and Development of the Settlement Network in Bulgaria, MTRS-NCTRZHP, Fores Publishing House, Sofia (1995).

Received June 21, 2021 